\title{
Preliminary study on the awareness of the SDGs in future primary school teachers
}

\author{
Ana M. Vernia-Carrasco', Victoria Pastor-Fuentes ${ }^{2}$, Miguel A. López-Navarro ${ }^{3}$ \\ ${ }^{1}$ Education and Specifics Didactics, Universitat Jaume I, Spain, ${ }^{2}$ Higher School of \\ Technology and Experimental Sciences, Universitat Jaume I, Spain, ${ }^{3}$ Business \\ Administration and Marketing, , Universitat Jaume I, Spain.
}

\begin{abstract}
This preliminary study has been carried out with the objective of knowing the sensitivity and implication of future primary school teachers regarding the 17 Sustainable Development Goals. The questionnaire used was translated from the work of Niklas Gericke et al. (2018), some questions elaborated on the basis of UNESCO's definition of sustainable development, aimed at knowing the awareness that people show towards sustainability. In the proposal of these authors, knowledge, attitudes and environmental, social and economic behavior were measured. In our study, whose representative sample has been $3 r d$ grade students in primary school teacher, of the Jaume I University, the same parameters have been used. The results we found were positive to the extent that we showed that the sample has an acceptable knowledge, as well as an implication and responsibility on the subject. As conclusions, we can highlight the need to include the subject in teacher training, with the aim of improving, not only awareness and responsibility in the climatic situation, but also in people's quality of life, the use of Material resources in addition to promoting educational, social and personal values, as a way of prevention and positive actions connected with the 17 SDGs. Music should be highlighted as an important factor in the training and awareness of future teachers.
\end{abstract}

Keywords: SDG1; university2; sustainable development3; teaching4; music5. 


\section{Introduction}

Our proposal places music education as a possible tool to implement the Sustainable Development Goals (SDGs) in primary school. However, the first step we take is the teacher training of the future primary school teacher. In our view, SDG number 4, referring to Education, is the basis for the achievement of the rest of the SDGs, understanding that poverty and hunger are fundamental, and education will be the tool that will provide empowerment and employability.

\section{Theorical framework}

The role that music plays in teacher training, we consider to be crucial, especially from the teaching of musical expression. In addition to being part of the culture of the people, certain investigations, as Moreno Fernández (2018) explains, have been directed to investigate the connections between culture, sustainability, social and economic development. This author points out that there are more and more festivals and events for social promotion and sustainable development. In Sanfeliu's opinion (2010 in Moreno Fernández, 2018), research on climate change from musical responses should be taken into account, highlighting musical and environmental activism, both in urban and traditional music and in classical music

A proof is found in the Ecoarte project, which links the scientific field with art. In this sense, Sanfeliu (2010) explains that, in order to fight against environmental problems, it is necessary, in addition to science, creativity that brings the future assumptions of the planet's situation closer to the imagination, therefore, the Arts can contribute to the Improvement of the overall quality of life.

Another example is found in the quality of life and sustainability, such as the orchestra of recycled instruments, which in addition to including social and educational inclusion, art and culture, raise awareness of the responsibility in the use of materials and their recycling, joining together music and sustainability. As Gómez (2016) explains, orchestra composed of children and young people with a complicated situation of risk of social exclusion has been able to improve their situation thanks to Favio Chávez, its director. With the motto The world sends us garbage and we return music, they have been able to give a clear example of how SDGs and music can unite their potential.

As Gutiérrez Martínez (2016) explains, sound can affect the therapeutic level, changing aspects that affect the physical, mental or spiritual realm, providing an improvement in the state of well-being. But, in addition, the musical activities that require a group, provide the acquisition of values such as participation, cooperation, respect, empathy, companionship or synergy. This means empowering people to acquire resilience, turning music into a tool that facilitates resilience, through sound and to overcome adversities. In this line, R. Williams, 
emphasizes that hegemony is achieved when the dominant culture uses education, philosophy, religion, advertising and art, thus allowing the heterogeneous groups that form society to be included in a natural way (Miller, T. and Yudice, G., 2004).

Taking the principles of UNESCO (2012) on sustainable development, we rely on culture as an underlying dimension to the three pillars on which sustainability is based: environment, society and economy.

Areas of the school that contribute to teaching and learning about sustainability, according to the UNESCO document (2012), would be:2.1. Example of Subsection

Documents should have no more than three levels of headings, which will be numbered with Arabic numerals starting at 1 . The title of the paper should be printed in Times New Romab 13 pt bold. The heading of each section should be printed in Times New Roman 11pt bold. The heading of each subsection should be printed in Times New Roman 10pt italics.

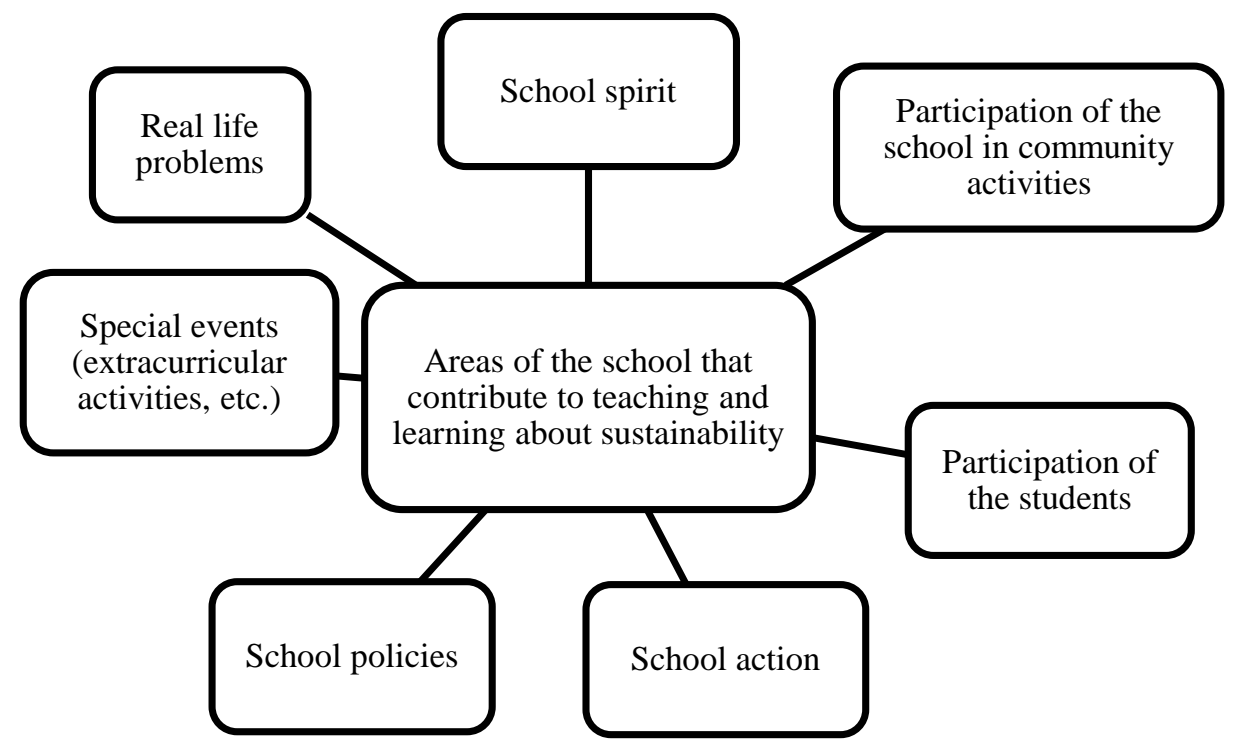

Figure 1. Areas of the school that contribute to teaching and learning about sustainability, according to the UNESCO document (2012)

\section{Methonolgyc framework}

The questionnaire used was translated from the work of Niklas Gericke et al. (2018), some questions elaborated on the basis of UNESCO's definition of sustainable development, aimed at knowing people's awareness of sustainability. In the proposal of these authors, knowledge, attitudes and environmental, social and economic behavior were measured. In our study, 
whose representative sample has been 3rd grade students in primary school teacher, of the Jaume I University, the same parameters have been used.

The resulting sample $\mathrm{n} 33$ was randomly selected, from a total of more than 80 third grade students in primary school teacher. The students had access to googleform, translated and adapted by the research team. Participation was voluntary and anonymous. I do not know gave any previous information to the participants, regarding the importance of the 17 Sustainable Development Goals (SDGs).

\subsection{Analysis of the results}

Although for the most part, the student body has an awareness that you could qualify as normal, considering that this normality would be a concern for sustainability and the environment, we detected some issues. Controversial, for example, in the concern about natural disasters or quality of life. Also in the exercise of democratic rights or infectious diseases, which do not consider a connection with sustainability. On the other hand, we highlight the economic understanding, as relevant in 57\% and the eradication of poverty with approximately $46 \%$, although when it comes to attitudes, they do consider reducing poverty by $85 \%$.

Addressing the actions, it is remarkable the consideration, in $76 \%$, of the usefulness of natural resources, as well as the need for stricter laws in this regard. 97\% believe it is important to take action against climate change. Releasing the use of water. Regarding knowledge on these issues, $94 \%$ consider it necessary, and in this same percentage the need to have the same opportunities is recognized, both for men and women. On the other hand, they only consider in $22 \%$ very important that those who pollute more, also contribute more, economically.

As for behaviors, only $42 \%$ consider it very important to use vehicles that do not contaminate. They also acknowledge not making good use of water, nor are they aware of garbage in spaces other than their own, they do not reflect on their behavior regarding the environment, by $37 \%$. However, the lifestyle has been changed, with respect to waste reduction. Another important aspect is the awareness of the behaviors related to health, almost $9 \%$ consider it relevant. Also the behavior towards other people who live in poverty, is only very important in $17 \%$.

Both the option of second-hand purchases and avoiding purchases in stores or brands with a bad reputation, is an option that is considered, not with a high percentage, but if it is taken into account. Based on the results, we consider, on the one hand, to modify the questionnaire and validate it, to adapt to the reality of the 17 SDGs and the information that needs to be known, both by the student body and the teaching staff. On the other hand, the training and awareness of the SDGs is considered necessary, in order to be reflective and to be able to 
reach the implementation in the teaching guides and in the study programs, of the importance in knowledge and behavior.

Below, we can see some of the 44 figures that are part of the results:

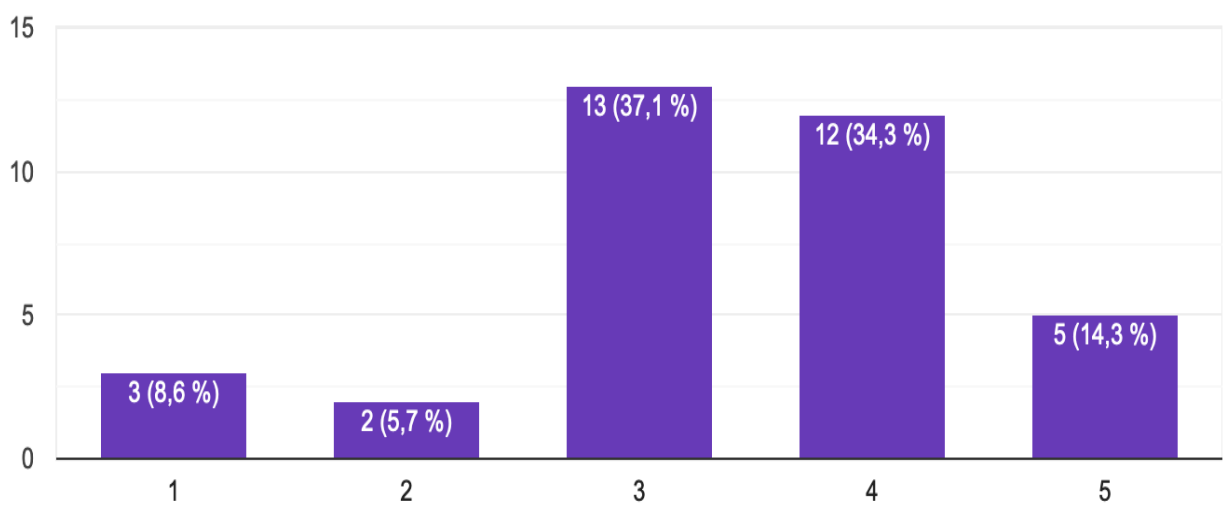

Figure 2. Relationship of sustainable development with natural disasters

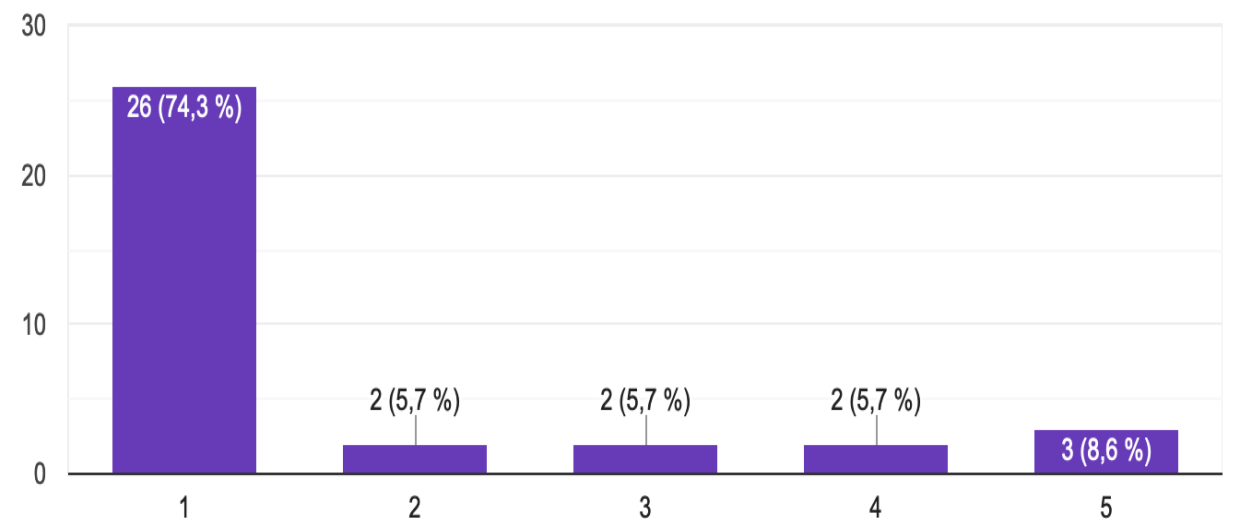

Figure 3. Untilization of natural resources for health and well-being 
15

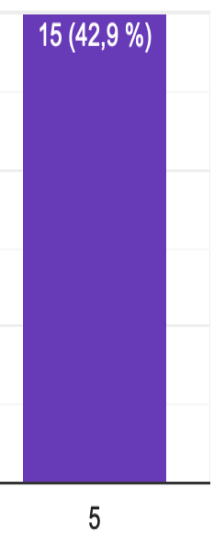

Figure 4. Use of non-polluting vehicles

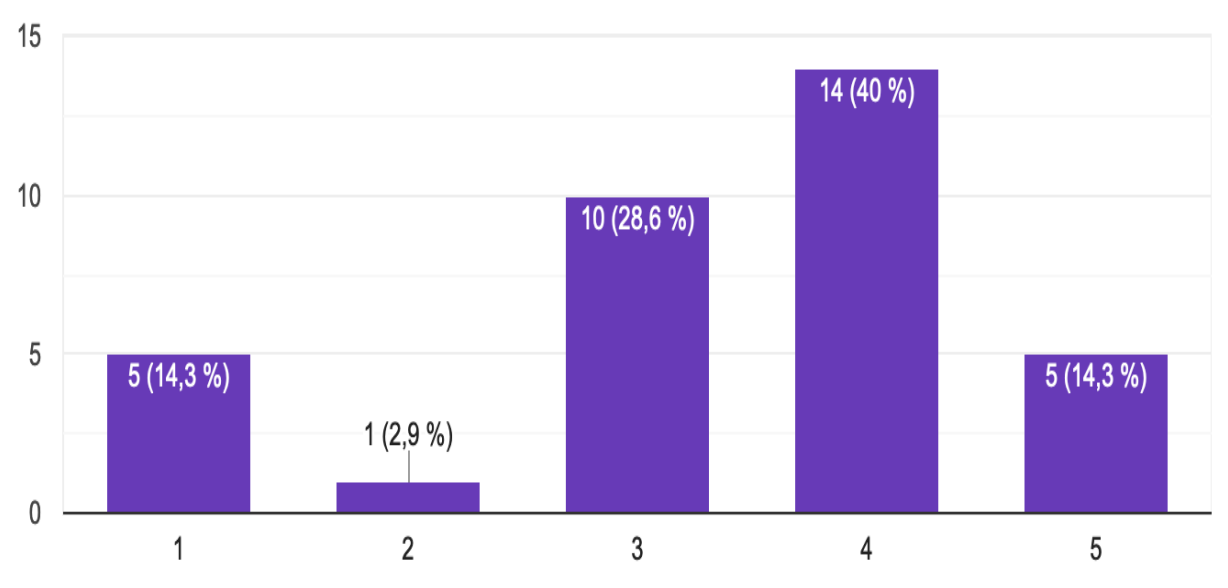

Figure 5. Garbage collection 


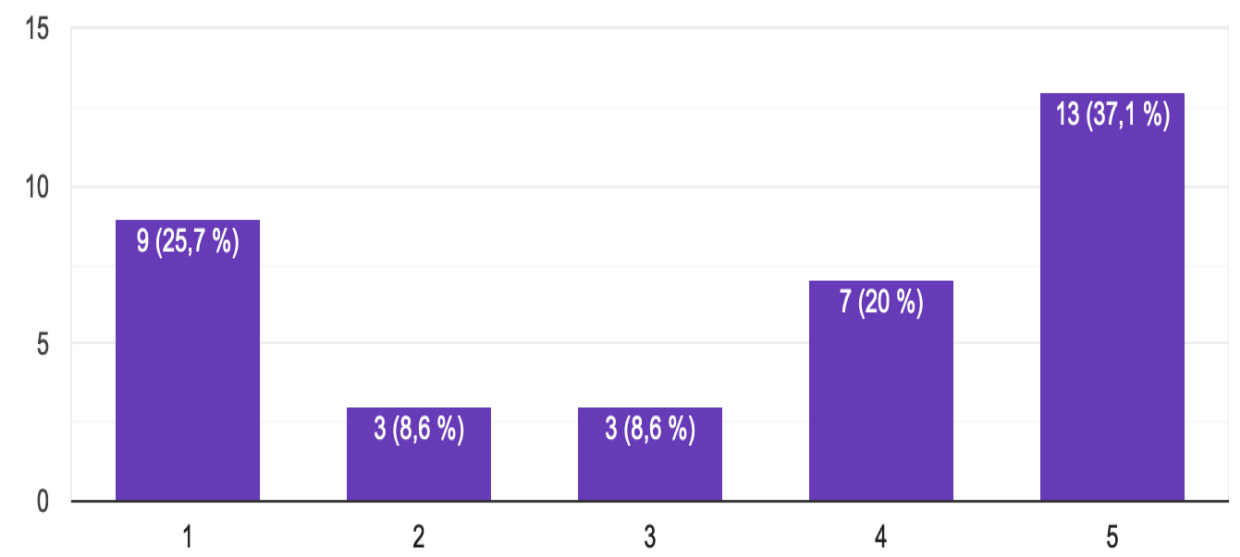

Figure 6. collaboration with humanitarian organizations and the environment

\section{Conclusion}

In conclusion, we can say that education, in our view, is the perfect tool to raise public awareness about responsibility for the accomplishment of the SDGs. Music, meanwhile, can be the main thread and connecting element for the education and training of future primary school teachers. The need for quality training includes creativity, critical spirit and the promotion of cultural manifestations that can be approached by teachers and students from music education. In addition, music drives responsible education, generates new behavior habits and recovers values of commitment and solidarity.

\section{References}

Gutiérrez Martínez, A.M. (2016). La música en la intervención holística. Aplicaciones clínicas y educativas. (Tesis Doctoral). Universidad de Córdoba. Córdoba. Disponible en: https://dialnet.unirioja.es/servlet/tesis?codigo=56826 [Fecha de consulta: 26 de abril de 2019]

Miller, T. y Yúdice, G. (2004). Política Cultural. Barcelona: Gedisa Editorial Gómez, B. (2016). La Orquesta de Instrumentos Reciclados de Cateura le pone música a 2017. El diario.es. Disponible en: https://www.eldiario.es/edcreativo/blogs/envases-alcubo/Orquesta-Instrumentos-Reciclados-Cateura-musica_6_596050418.html [Fecha de consulta: 26 de abril de 2019]

Moreno Fernández, S. (2018), Música, ecología y desarrollo sostenible en el nordeste transmontano. Trans. Revista Transcultural de Música [en linea] 2015, Disponible en: http://www.redalyc.org/articulo.oa? id=82242883005 [Fecha de consulta: 26 de mayo de 2019] 
Sanfeliu, A. 2010. La música y el medio ambiente. Barcelona: Escola de cultura de pau. Institut Català internacional per la pau, publicación electrónica. Disponible en: http://ddd.uab.cat/pub/butecpspa/butecpspa_a2010m10n2/musicaymedioambiente.pdf [Fecha de consulta: 26 de mayo de 2019]

UNESCO. (2012). Educación para el Desarrollo Sostenible. Libro de consulta. Recuperado de: http://unesdoc.unesco.org/images/0021/002167/216756s.pdf [Fecha de consulta: 26 de mayo de 2019]

UNESCO (s/f). Desglosar el Objetivo de Desarrollo Sostenible 4 Educación 2030 Disponible en: http://unesdoc.unesco.org/images/0024/002463/246300s.pdf [Fecha de consulta: 20 de mayo de 2019] 